\title{
The Good and the Bad of Poisonous Plants: an Introduction to the USDA-ARS Poisonous Plant Research Laboratory
}

\author{
Kevin D. Welch • Kip E. Panter • Dale R. Gardner • \\ Bryan L. Stegelmeier
}

Published online: 25 February 2012

(C) American College of Medical Toxicology (outside the USA) 2012

\begin{abstract}
This article provides an overview of the Poisonous Plant Research Laboratory (PPRL), about the unique services and activities of the PPRL and the potential assistance that they can provide to plant poisoning incidences. The PPRL is a federal research laboratory. It is part of the Agricultural Research Service, the in-house research arm of the U.S. Department of Agriculture. The mission of the PPRL is to identify toxic plants and their toxic compounds, determine how the plants poison animals, and develop diagnostic and prognostic procedures for poisoned animals. Furthermore, the PPRL's mission is to identify the conditions under which poisoning occurs and develop management strategies and treatments to reduce losses. Information obtained through research efforts at the PPRL is mostly used by the livestock industry, natural resource managers, veterinarians, chemists, plant and animal scientists, extension personnel, and other state and federal agencies. PPRL currently has 9 scientists and 17 support staff, representing various disciplines consisting of toxicology, reproductive toxicology, veterinary medicine, chemistry, animal science, range science, and plant physiology. This team of scientists provides an interdisciplinary approach to applied and basic research to develop solutions to plant intoxications. While the mission of the PPRL primarily impacts the livestock industry, spinoff benefits such as development of animal models, isolation and characterization of novel compounds, elucidation of biological and molecular mechanisms of action, national and international collaborations, and outreach efforts are significant to biomedical researchers. The staff at the PPRL has extensive knowledge regarding a number of
\end{abstract}

K. D. Welch $(\bowtie) \cdot$ K. E. Panter · D. R. Gardner · B. L. Stegelmeier Poisonous Plant Research Laboratory, Agriculture Research Service, United States Department of Agriculture,

1150 E. 1400 N.,

Logan, UT 84341, USA

e-mail: kevin.welch@ars.usda.gov poisonous plants. Although the focus of their knowledge is on plants that affect livestock, oftentimes, these plants are also poisonous to humans, and thus, similar principles could apply for cases of human poisonings. Consequently, the information provided herein could be of benefit to healthcare providers for human cases as well.

Keywords Poisonous plants · Chemical analysis · Plant toxins $\cdot$ Toxicology $\cdot$ Plant identification

\section{Introduction}

In the late 1800s, settlers migrated west with their livestock, and large losses began to occur as their animals encountered unfamiliar range plants. As a result of these losses, stockmen pleaded for help from the federal government. Dedicated research efforts were established by federal mandate around 1894. Early researchers traveled west each spring and summer to temporary field stations established in locations where the largest losses of livestock occurred. A permanent research location was created for the Poisonous Plant Research Laboratory (PPRL) in 1955 on the campus of Utah State University, Logan, UT, USA. In 2004, a new research laboratory was dedicated providing additional space and resources. Scientists at the PPRL provide information to and have active collaborations with scientists around the USA and all over the world including China, Brazil, South Africa, Croatia, and Australia.

The mission of the PPRL is to identify toxic plants and their toxic compounds, determine how the plants poison animals, and develop diagnostic and prognostic procedures for poisoned animals. Furthermore, PPRL's mission is to identify conditions under which poisoning occurs and develop management strategies and treatments to reduce 
losses. The PPRL currently has 9 scientists and 17 support staff, representing various disciplines consisting of toxicology, reproductive toxicology, veterinary medicine, chemistry, animal science, range science, and plant physiology. This team of scientists provides an interdisciplinary approach to applied and basic research to develop solutions to intoxication. Major projects that are currently under investigation at PPRL encompass a variety of plants and can be reviewed on the PPRL website (http://www.pprl.ars.usda.gov). Criteria for selecting research problems vary but typically include scope of the problem (e.g., local, regional, or national importance), severity of the losses, in both animal numbers and financial terms, current focus of the research team, and uniqueness of the poisoning problem. Table 1 lists many of the plants that PPRL scientists have researched in the past or are currently studying. Table 2 is a list of the plant toxins for which PPRL scientists actively perform analyses.

PPRL scientists are currently pursuing five areas of investigation. These areas include (1) developing sciencebased guidelines for grazing livestock on rangelands infested with toxic plants; (2) reducing the risks of livestock losses due to variations in quantitative and qualitative differences in toxin accumulation over time and in plant species by quantifying the influence of endophytes, climate changes, and genotype on plant toxin accumulation; (3) enhancing feed and food safety by improving risk assessment and diagnosis of plant-induced poisoning to livestock by improving analytical methods for analyzing plant and animal tissues, measuring toxicokinetics, assessing carcinogenic and genotoxic potential, and identifying toxin metabolites and biomarkers of toxicoses; (4) developing improved procedures and guidelines for diagnostic and prognostic

Table 1 Poisonous plants for which the PPRL has information/recommendations for livestock poisonings

\begin{tabular}{|c|c|c|}
\hline Arrowgrass & Horsebrush & Ponderosa pine \\
\hline $\begin{array}{l}\text { Western } \\
\text { bracken fern }\end{array}$ & Horsetail & Rayless goldenrod \\
\hline Bitter rubberweed & Jimsonweed & $\begin{array}{l}\text { Selenium-accumulating } \\
\text { plants }\end{array}$ \\
\hline Broom snakeweed & Larkspur & Sneezeweed \\
\hline Chokecherry & Locoweed & Spring parsley \\
\hline Cocklebur & Lupine & St. Johnswort \\
\hline Copperweed & Milkvetch & Tansy mustard \\
\hline Death camas & Milkweed & Tansy ragwort \\
\hline Desert baileya & $\begin{array}{l}\text { Nitrate-accumulating } \\
\text { plants }\end{array}$ & Riddell's groundsels \\
\hline $\begin{array}{l}\text { Drymary or } \\
\text { inkweed }\end{array}$ & Oak & Water hemlock \\
\hline False hellebore & Colorado rubberweed & Yellow star thistle \\
\hline Halogeton & Poison hemlock & Yew \\
\hline Hemp dogbane & & \\
\hline
\end{tabular}

evaluation to reduce negative impacts of poisonous plants on livestock reproduction and embryo/fetal growth; and (5) developing guidelines to aid producers and land managers in making genetic-based herd management decisions to improve livestock performance and animal safety on rangelands infested with poisonous plants.

\section{Methods to Identify Plant Poisonings in Livestock}

The PPRL provides information and support to livestock owners, managers, veterinarians, and extension agents to help them determine if an animal was poisoned by a plant. Despite the high frequency of occurrence, arriving at a positive diagnosis of plant poisoning is challenging. To help make an accurate diagnosis, a history of the poisoning incident is obtained, which includes understanding the animal involved, the location, plant communities involved, and management strategies being used (Table 3). Compiling animal information such as type of animal, overall condition, age, sex, vaccination histories, and nutritional status as well as identifying clinical signs, lesions, number of affected animals, and progression of disease are the first steps in identifying a cause. Once this information is gathered, a list of potential causes is developed. This list is used to develop an investigative plan that focuses on confirming the right diagnosis and excluding all other possibilities. Making a complete and thorough list requires engagement of appropriate experts when needed (Table 4). Many infectious, degenerative, and immunologic diseases produce clinical signs, biochemical changes, and lesions identical to those caused by poisonous plants and thus must be ruled out. An extensive differential diagnosis is created so that a plan can be formulated to confirm or rule out possible causes. The plan includes field investigations, physical examinations, biochemical or serologic evaluations of the blood, possible postmortem evaluations, and chemical or microscopic evaluations of plants and/or animal tissues (Tables 3 and 5). Rapid institution of this process oftentimes allows for an accurate diagnosis, practical solutions, and aids in avoidance of catastrophic animal losses.

Scientists at the PPRL help with plant poisoning incidences by identifying poisonous plants and analyzing plant and animal tissues for plant toxins. Plants that are included in the list of differential diagnoses or unidentified plants are collected for positive identification. The entire plant is collected if possible or a high-quality photograph if it is the only option. Flowering plants are most easily identified. Most state land grant (agricultural) colleges have herbaria with experts able to identify most plants. However, if local options are not readily available, scientists at the PPRL can help. Additionally, due to the fact that the toxicity of a plant is often variable, additional plant samples are oftentimes needed for chemical evaluation 
Table 2 Plants and plant toxins commonly analyzed at PPRL

\begin{tabular}{llll}
\hline Plant scientific names & Plant common names & Class of toxin & Examples of toxin \\
\hline Delphinium spp. & Larkspurs & Norditerpenoid alkaloids & Methyllycaconitine, deltaline \\
Astragalus and Oxytropis spp. & Locoweeds & Indolizidine alkaloids & Swainsonine \\
Astragalus spp. & Vetches & Nitrotoxins & 3-Nitropropanol \\
Astragalus spp. & Selenium accumulator plants & mineral & Selenium \\
Lupinus spp. & Lupines & Quinolizidine and piperidine alkaloids & Anagyrine, ammodendrine \\
Senecio spp., Crotalaria & Tansy ragwort, Riddell's groundsel & Pyrrolizidine alkaloids & Riddelliine \\
Zigadenus spp. & Death camas & Steroidal alkaloids & Zygacine \\
Veratrum spp. & Skunk cabbage, corn Lily, false hellebore & Steroidal alkaloids & Cyclopamine, veratramine \\
Pinus and Juniperus spp. & Ponderosa pine, juniper trees & Labdane acids & Isocupressic acid \\
Conium maculatum & Poison hemlock & Pyridine alkaloids & Coniine \\
Cicuta maculata & Water hemlock & Acetylenic alcohols & Cicutoxin \\
\hline
\end{tabular}

of potential toxins. It is best to contact the appropriate laboratory prior to submission to ensure the sample is properly prepared and that an adequate sample size is being sent.

\section{Biomedical Applications of Poisonous Plant Research}

While the mission of the PPRL primarily impacts the livestock industry, spinoff benefits such as development of animal models, isolation and characterization of novel compounds, elucidation of biological and molecular mechanisms of action, national and international collaborations, and outreach efforts are significant to biomedical researchers. Traditionally, searches for new drugs in human medicine investigate plants that have an ethnopharmacological basis for their use, whereas plants that are commonly poisonous to livestock have been less well studied. However, numerous advances in understanding and potentially treating human diseases have resulted from investigations of the toxic principles derived from poisonous plants that are commonly responsible for livestock

Table 3 Components essential for an accurate diagnosis in suspected plant poisoning episodes

History of the poisoning incident: (this includes all information and analyses already performed)

Pertinent facts: breed, sex, age, number, condition, vaccination status, mineral supplements, feeding or pasture changes, and other treatments Clinical disease: number affected, signs, clinical course and progression, lesions, and mortality

Clinical tests: blood tests to evaluate inflammation and organ function and to evaluate immunologic responses to infectious agents (blood cell counts and serum element, metabolite and biochemical analyses, and serologic tests)

Field studies: (this includes additional evaluations and analyses to be performed)

Animals: general condition of affected animals, unusual behaviors, clinical signs, and lesions. Additional clinical tests may be indicated to analyze samples for plant toxins or metabolites in the tissues, blood, urine, or feces

Pasture:

1. Determine forage availability, plant species composition, and evidence of grazing patterns

2. Collection of potential problem plants or unidentified plants (dried samples for identification, frozen samples for chemical analysis)

3. Note physical location, weather conditions at the time of the incident (for example, snow depth) and their effect on forage and forage availability

Prepared feeds such as hay, silage, or concentrate feed samples (frozen for analysis)

Water, salt, and mineral supplements including location and use (samples frozen for analysis)

Check for other potential hazards, such as old batteries and pesticide-laced feed

\section{Postmortem examination:}

Animal condition and lesions

Rumen and gastrointestinal tissues and contents

Tissues for histologic studies fixed in 10\% neutral buffered formalin (brain, lung, heart, liver, spleen, gastrointestinal tract, kidney, skeletal muscle, and any gross lesions)

Tissues for chemical or microscopic studies stored in plastic bags and frozen (rumen and gastrointestinal contents, complete eye, liver, kidney, serum, whole blood, body fat, bone, urine, and milk if lactating) 
Table 4 Resource list

USDA/ARS Poisonous Plant Research Laboratory

Tel: +1-435-7522941

http://www.pprl.ars.usda.gov

State agricultural extension service

http://www.csrees.usda.gov/Extension

State animal disease diagnostic laboratory

http://www.aavld.org/index.php?

option $=$ com_content\&view $=$ article $\&$ id $=18 . \mathrm{Id}=$ aavld

(laboratories accredited by American Association of

Veterinary Diagnostic Laboratories)

Local herbarium

http:/herba.msu.ru/mirrors/www.helsinki.fi/kmus/botmus.html (lists of public herbaria throughout the world)

Microscopic analysis of feces and ingesta

Texas Veterinary Medical Diagnostic Laboratories

Tel: +1-888-6465623

http://tvmdl.tamu.edu

poisoning. The following are a few examples of how information gained through livestock-based research efforts have also resulted in human biomedical applications.

\section{Cancer Therapy}

During the mid-20th century, up to $25 \%$ of pregnant ewes that grazed in the mountains of central Idaho gave birth to lambs suffering from serious craniofacial defects [1]. These anomalies varied from the extreme malformation, cyclopia, to mildly deformed upper jaws. Ingestion of Veratrum californicum by sheep on day 14 of gestation was shown to induce severe birth defects in offspring [2]. Although Veratrum is relatively unimportant as a plant poisonous to adult sheep, it is extremely toxic to a developing embryo. Experiments also showed that the damage to the developing embryo can be severe enough to cause embryonic death [3]. Scientists at the PPRL determined that the primary alkaloid responsible for Veratrum-induced terata was 11-deoxojervine, which was named cyclopamine. In addition to sheep, cyclopamine induced craniofacial defects in rabbits and chick embryos [4]. Recent advances in molecular biology and genetics have demonstrated that the molecular mechanisms underlying the induction of terata by cyclopamine are due to the inhibition of the sonic hedgehog signaling pathway. Studies using a variety of sonic hedgehog-dependent cell types have shown that virtually all aspects of sonic hedgehog signaling are interrupted upon exposure to cyclopamine $[5,6]$. These studies concluded that the cyclopamine exerts its primary teratogenic

Table 5 Partial list of tests, samples, sample size, and preservation for investigation of potential poisonous plant poisoning

\begin{tabular}{|c|c|c|c|}
\hline Test & Sample & Size & Shipping \\
\hline Blood counts & Whole blood & $3-5 \mathrm{~mL}$ & Chilled on ice \\
\hline Serum biochemistries & Serum & $5-10 \mathrm{~mL}$ & $\begin{array}{l}\text { Chilled on ice or if frozen, serum } \\
\text { should be separated from the cells }\end{array}$ \\
\hline $\begin{array}{l}\text { Microscopic evaluation } \\
\text { of tissues }\end{array}$ & Various tissues & $1 \times 1 \times 2$-in pieces & Fixed formalin \\
\hline Postmortem or necropsy & Dead or moribund animal & Whole animal & Fresh \\
\hline $\begin{array}{l}\text { Chemical evaluation of serum, } \\
\text { blood, urine, or milk }\end{array}$ & $\begin{array}{l}\text { Serum, whole blood, } \\
\text { urine, or milk }\end{array}$ & $20 \mathrm{~mL}$ & $\begin{array}{l}\text { Stored in plastic tubes on } \\
\text { ice or frozen }\end{array}$ \\
\hline Chemical evaluation of tissue & Various tissues & $2 \times 2 \times 4$-in pieces & Stored in plastic bags and frozen \\
\hline $\begin{array}{l}\text { Chemical evaluation of } \\
\text { feces or gastrointestinal contents }\end{array}$ & Feces or ingesta & $\begin{array}{l}1-2 \text { lbs (about a } \\
\text { sandwich bag full) }\end{array}$ & Stored in plastic bags and frozen \\
\hline Plant identification & Whole plant & $\begin{array}{l}\text { Whole plant including flowers, } \\
\text { pods, leaves, stems, and roots }\end{array}$ & $\begin{array}{l}\text { Fresh if delivered that day, dried } \\
\text { if hand-delivered later, pressed } \\
\text { and dried if shipped }\end{array}$ \\
\hline Plant chemical analysis & Whole plants & 5 or 6 whole plants & $\begin{array}{l}\text { Fresh if delivered that day, dried } \\
\text { if shipped, or frozen if they can be } \\
\text { maintained frozen during shipping }\end{array}$ \\
\hline $\begin{array}{l}\text { Hay for weed contamination } \\
\text { and weed identification }\end{array}$ & Stored baled hay & 5 or 6 bales & Dry \\
\hline Hay for nitrate analysis & Hay & $\begin{array}{l}\text { Several representative samples } \\
\text { (these can be core samples), } 1-2 \mathrm{lbs}\end{array}$ & Dry \\
\hline Prepared feeds & Feeds & $\begin{array}{l}\text { Representative feed samples } \\
\text { such as cubed feed, } 1-2 \mathrm{lbs}\end{array}$ & Dry \\
\hline Silage or green-chopped feed & Feeds & Representative feed samples, 5-10 lbs & Frozen \\
\hline
\end{tabular}

Be sure to check with the laboratory because they often require specific sampling, sample preparation, and shipping instructions. Label all materials with ink, provide date, owner, location and contact information 
effect on developing embryos by selectively blocking sonic hedgehog signal transduction [5, 6]. Consequently, cyclopamine has become a valuable research tool to study the sonic hedgehog signaling pathway and its biological effects. The sonic hedgehog signaling pathway is not only essential for proper embryonic development but it also plays a role in the division of adult cells. Thus, this signaling pathway has been shown to be involved in the formation of several cancers [7, 8]. Consequently, several pharmaceutical companies are currently testing derivatives of cyclopamine as potential therapeutics [9].

\section{Skeletal Malformations}

Research at the PPRL on plant-induced skeletal malformations and cleft palate began in the late 1950s when musculoskeletal defects in newborn calves known as "crooked calf disease" were attributed to maternal ingestion of Lupinus spp. $[10,11]$. A high incidence of cleft palate was also associated with lupine-induced crooked calf disease $[12,13]$. In the late 1960s and early 1970s in the Midwestern and Southern states, epidemic proportions of skeletal malformations in pigs were recorded. It was determined that poison hemlock (Conium maculatum) and burley tobacco (Nicotiana tabacum) were responsible. The induced malformations in newborn pigs appeared similar to those in lupine-induced crooked calf disease.

The proposed mechanism of action for Lupinus-induced malformations and cleft palate has been attributed to reduction in fetal movement [14]. The mechanism of action of the teratogenic effects of Lupinus, Conium, and Nicotiana spp. is believed to be identical [15]. Experiments using ultrasound demonstrated a direct relationship between reduced fetal activity and severity of contracture-type skeletal defects and cleft palate in sheep and goats. Further research suggested that this inhibition of fetal movement must be over a protracted period of time during specific stages of gestation. The skeletal malformations are theoretically caused by abnormal alignment, bowing, or twisting as a result of the in utero positioning and/or abnormal tendon and ligament development resulting from the lack of movement [14]. The cleft palate is believed to result from mechanical interference by the tongue between the palatal shelves at the programmed time of closure $[16,17]$.

Although the goat model was primarily developed to study the mechanism of action of crooked calf syndrome in cattle, this model has become an important tool in the study of the mechanism of cleft palate induction in humans and fetal biomedical research $[18,19]$. Currently research is focused on the privileged period of fetal scarless healing and development of in utero surgical procedures to repair human cleft palates early in gestation. The methodology and techniques used to successfully repair congenital cleft palates in utero with successful scarless palatal healing and development after repair have been demonstrated [19]. This model is also useful for histological comparison of the prenatal and postnatal-repaired cleft palate and for comparison of craniofacial growth and development. Therefore, the goat model provides an ideal congenital model to study the etiology of cleft palate in humans, develop fetal surgical techniques in utero, and compare palate histology after prenatal or postnatal repair.

Even though research at the PPRL has been limited to the three genera mentioned above, there are many other plant species that contain structurally similar alkaloids. These include species of the genera Genista, Prosopis, Lobelia, Cytisus, Sophora, Pinus, Punica, Duboisia, Sedum, Withania, Carica, Hydrangea, Dichroa, Cassia, Ammondendron, Liparia, Colidium, and others. Many of these plants may be included in human diets; however, toxicity and teratogenicity are a matter of dose, rate of ingestion, time of insult, and alkaloid concentration and composition in the plant, and thus toxicity/teratogenicity may not always be readily correlated with ingestion. Of note, there is circumstantial evidence that the alkaloids in Lathyrus latifolius may have been the cause of arm and hand deformities in a baby boy, via maternal ingestion of goat's milk [20].

\section{Glycoprotein Processing}

Some of the earliest research undertaken by the U.S. Department of Agriculture (USDA) (PPRL) to prevent widespread livestock losses was focused specifically on locoweeds. Consumption of locoweeds by animals produces a multitude of syndromes, including neurological problems, depression, emaciation, reproductive disturbances, birth defects, and abortion. Specific problems observed are a consequence of numerous factors, including animal species, nutritional status, prior exposure to the plant, pregnancy, and environmental conditions [21]. For example, cattle grazing the plants at high altitudes exhibits congestive right-heart enlargement and edema of the brisket [22,23], with nursing calves exhibiting the symptoms prior to their mothers, indicating that the toxin is transferred in the milk. The primary toxic constituent of locoweeds was determined to be the indolizidine alkaloid swainsonine [24]. Swainsonine was first isolated and identified as the toxic constituent of Swainsona species, known as "poison peas," a genus of legumes restricted to Australia but closely related to the locoweeds both in physical appearance and also in their effects on livestock. The toxin has also been found in a number of Astragalus and Oxytropis species in other parts of the world, such as South America and areas of China. It has also been shown to occur in members of the morning glory family (Ipomoea species) that are poisonous to sheep in Australia and to goats in Mozambique and Brazil [25].

The chemical structure of swainsonine has many similarities to the simple sugar mannose, which it appears to mimic. 
As a result of this mimicry, swainsonine inhibits the enzyme $\alpha$-mannosidase, which trims sugar molecules from glycoproteins within the cell and thus is essential for the proper cellular function. Failure of the trimming process results in an accumulation of the glycoproteins within the cell until vacuolation results. After a sufficient number of cells have been damaged in this way, the signs of poisoning appear in the animal. Because all cells depend on the proper functioning of $\alpha$ mannosidase, many different organs can be damaged, including the brain, heart, reproductive system, and digestive system. The particular organs affected and signs of poisoning depend on the amount of swainsonine consumed and the period of exposure, as well as external factors such as nutritional status, grazing altitude, and pregnancy. Swainsonine is very water soluble and therefore distributed to many parts of the body. It is also rapidly excreted, primarily in the urine, but in lactating animals, a portion of it is transferred to the milk, such that nursing animals may become locoed [26, 27]. The fast excretion rate suggests that occasional consumption of locoweeds for short periods is unlikely to have serious adverse effects but that continuous consumption, even at relatively low levels, can result in poisoning.

The recognition that swainsonine was an inhibitor due to its mimicry of mannose suggested that structurally similar alkaloids might have similar properties. One such alkaloid, castanospermine, has been isolated from seeds of Moreton Bay chestnut (Castanospermum australe). Other scientists found that castanospermine was a potent inhibitor of glucosidases, enzymes that are also essential for glycoprotein processing [28]. The large leguminous seeds, which litter the ground beneath the trees, had been known to be toxic to livestock, especially cattle and horses and, even on occasion, humans [29]. The discovery of the biochemical activity of this alkaloid therefore suggested a close analogy to locoweed poisoning. Glycosidase-inhibitory alkaloids, which were initially represented by swainsonine alone, have now expanded to encompass a number of structural classes including indolizidines, pyrrolizidines, tropanes, and simpler pyrrolidine and piperidine analogues. Their bioactivity has stimulated the synthesis of counterparts. To include so many disparate structural types under a single classification, the generic name of "polyhydroxy alkaloids" has been applied because the presence of multiple hydroxyl groups is a consistent feature [30].

The fundamental cellular function of glycoprotein processing primarily affects $\mathrm{N}$-linked glycoproteins, which are involved in numerous essential physiological functions, especially cell-cell recognition reactions critical to pathogenesis, inflammation, parasitism, development, cell adhesion, and symbiosis. Consequently, as might be expected from a class of compounds that inhibits glycosidases, the polyhydroxy alkaloids exhibit an exceptional diversity of biological effects, including insecticidal, herbicidal, antimicrobial, and therapeutic activities. Discovery and isolation of many of the alkaloids has been a result of observations of the ultimate clinical effects that result from the consumption by animals of plants containing these bioactive compounds. The capability of polyhydroxy alkaloids to disrupt the general cellular function of glycoprotein processing leads to the expectation that these compounds may have therapeutic potential for the treatment of various diseases. Investigation of the alkaloids for therapeutic potential has so far concentrated on the treatment of cancer and inhibition of metastasis, as antiviral agents and as antiparasitics. Structurally related compounds have also been used as antidiabetic drugs [31]. Awareness of these alkaloids first arose because of their effects as the toxic components of poisonous plants, but many are now being identified in plants not established as toxic and even in common food plants for humans, including tomatoes, potatoes, eggplants, and sweet potatoes [32].

\section{Summary}

The PPRL is a USDA research laboratory that studies plants that poison livestock; however, many of these plants are also toxic to humans. Additionally, many plant toxins have been adopted as tools for biomedical investigations from plants that were first investigated for the problems inflicted on the livestock industry. It is probable that more toxins from poisonous plants, only now being investigated, will also prove to have biomedical applications. Scientists at the PPRL are willing to help with poisoning incidences in any manner they can including plant identification and toxin analysis.

Source of Funding The PPRL is a federal research laboratory which is funded by congressional mandate.

Conflicts of Interest None.

\section{References}

1. James LF (1999) Teratological research at the USDA-ARS poisonous plant research laboratory. J Nat Toxins 8(1):63-80

2. Binns W, Shupe JL, Keeler RF, James LF (1965) Chronologic evaluation of teratogenicity in sheep fed Veratrum californicum. J Am Vet Med Assoc 147(8):839-842

3. Van Kampen KR, Binns W, James LF, Balls LD (1969) Early embryonic death in ewes given Veratrum californicum. Am J Vet Res 30(4):517-519

4. Keeler RF (1978) Cyclopamine and related steroidal alkaloid teratogens: their occurrence, structural relationship, and biologic effects. Lipids 13(10):708-715 
5. Cooper MK, Porter JA, Young KE, Beachy PA (1998) Teratogenmediated inhibition of target tissue response to Shh signaling. Science 280(5369):1603-1607

6. Incardona JP, Gaffield W, Kapur RP, Roelink H (1998) The teratogenic Veratrum alkaloid cyclopamine inhibits sonic hedgehog signal transduction. Development 125(18):3553-3562

7. Hatten ME, Roussel MF (2011) Development and cancer of the cerebellum. Trends Neurosci 34(3):134-142

8. Kelleher FC (2011) Hedgehog signaling and therapeutics in pancreatic cancer. Carcinogenesis 32(4):445-451

9. Gould A, Missailidis S (2011) Targeting the hedgehog pathway: the development of cyclopamine and the development of anticancer drugs targeting the hedgehog pathway. Mini Rev Med Chem 11(3):200-213

10. Shupe JL, James LF, Binns W (1967) Observations on crooked calf disease. J Am Vet Med Assoc 151(2):191-197

11. Shupe JL, Binns W, James LF, Keeler RF (1967) Lupine, a cause of crooked calf disease. J Am Vet Med Assoc 151(2):198-203

12. Shupe JL, James LF, Binns W, Keeler RF (1968) Cleft palate in cattle. Cleft Palate J 5:346-355

13. Shupe JL, Binns W, James LF, Keller RF (1968) A congenital deformity in calves induced by maternal consumption of lupin. Aust J Agric Res 19(2):335-340

14. Panter KE, Bunch TD, Keeler RF, Sisson DV, Callan RJ (1990) Multiple congenital contractures (MCC) and cleft palate induced in goats by ingestion of piperidine alkaloid-containing plants: reduction in fetal movement as the probable cause. J Toxicol Clin Toxicol 28(1):69-83

15. Panter KE, Gardner DR, Molyneux RJ (1994) Comparison of toxic and teratogenic effects of Lupinus formosus, L. arbustus, and $L$. caudatus in goats. J Nat Toxins 3(2):83-89

16. Panter KE, Keeler RF (1992) Induction of cleft palate in goats by Nicotiana glauca during a narrow gestational period and the relation to reduction in fetal movement. J Nat Toxins 1:25-32

17. Panter KE, Gardner DR, Molyneux RJ (1998) Teratogenic and fetotoxic effects of two piperidine alkaloid-containing lupines (L. formosus and L. arbustus) in cows. J Nat Toxins 7(2):131140

18. Weinzweig J, Panter KE, Pantaloni M, Spangenberger A, Harper JS, Lui F, Gardner D, Wierenga TL, Edstrom LE (1999) The fetal cleft palate: I. Characterization of a congenital model. Plast Reconstr Surg 103(2):419-428
19. Weinzweig J, Panter KE, Pantaloni M, Spangenberger A, Harper JS, Lui F, James LF, Edstrom LE (1999) The fetal cleft palate: II. Scarless healing after in utero repair of a congenital model. Plast Reconstr Surg 104(5):1356-1364

20. Kilgore WW, Crosby DG, Craigmill AL, Poppen NK (1981) Toxic plants as possible human teratogens. Calif Agric 35:6

21. James LF, Hartley WJ, Van Kampen KR (1981) Syndromes of Astragalus poisoning in livestock. J Am Vet Med Assoc 178 (2): $146-150$

22. James LF, Hartley WJ, Vankampen KR, Allen S (1981) Locoweed and congestive right heart-failure in cattle. J Am Vet Med Assoc 179(3):263

23. James LF, Panter KE, Broquist HP, Hartley WJ (1991) Swainsonine-induced high mountain disease in calves. Vet Hum Toxicol 33(3):217-219

24. Molyneux RJ, James LF (1982) Loco intoxication: indolizidine alkaloids of spotted locoweed (Astragalus lentiginosus). Science 216(4542):190-191

25. Molyneux RJ, McKenzie RA, O’Sullivan BM, Elbein AD (1995) Identification of the glycosidase inhibitors swainsonine and calystegine B2 in Weir vine (Ipomoea sp. Q6 [aff. calobra]) and correlation with toxicity. J Nat Prod 58(6):878-886

26. James LF, Hartley WJ (1977) Effects of milk from animals fed locoweed on kittens, calves, and lambs. Am J Vet Res 38(8):12631265

27. James LF (1972) Effect of locoweed on fetal development: preliminary study in sheep. Am J Vet Res 33(4):835-840

28. Saul R, Molyneux RJ, Elbein AD (1984) Studies on the mechanism of castanospermine inhibition of alpha- and betaglucosidases. Arch Biochem Biophys 230(2):668-675

29. Everist SL (1981) Poisonous plants of Australia. Angus and Robertson, Sydney

30. Watson AA, Fleet GW, Asano N, Molyneux RJ, Nash RJ (2001) Polyhydroxylated alkaloids - natural occurrence and therapeutic applications. Phytochemistry 56(3):265-295

31. Taylor RH, Barker HM, Bowey EA, Canfield JE (1986) Regulation of the absorption of dietary carbohydrate in man by two new glycosidase inhibitors. Gut 27(12):1471-1478

32. Asano N, Kato A, Matsui K, Watson AA, Nash RJ, Molyneux RJ, Hackett L, Topping J, Winchester B (1997) The effects of calystegines isolated from edible fruits and vegetables on mammalian liver glycosidases. Glycobiology 7(8):1085-1088 